УДК 008

DOI: 10.18101/1994-0866-2020-3-53-60

\title{
ЦИФРОВЫЕ ТЕХНОЛОГИИ КАК ФАКТОР ТРАНСФОРМАЦИИ КУЛЬТУРЫ
}

\author{
() Мешкова Людмила Николаевна \\ кандидат философских наук, доцент, \\ Пензенский государственный университет \\ Россия, 440026, г. Пенза, ул. Красная, 40 \\ lnmeshkova@rambler.ru
}

\begin{abstract}
Аннотация. В статье рассматривается влияние цифровых технологий на современный культурный процесс. Показано, что процесс цифровизации ведет к возникновению цифровой культуры, которая стала неотъемлемой частью деловой и повседневной жизни, создала новые возможности для проявления свободы человека, для личностной самореализации. В то же время с развитием цифровой культуры возникают новые моральные и правовые проблемы, связанные с безопасностью в киберпространстве. Отмечается, что актуальной проблемой стало взаимодействие цифровой культуры как культуры глобального типа с традиционной культурой. Консервативные установки традиционного сознания могут становиться препятствием для освоения новых цифровых технологий. Это является не только одной из причин цифрового разрыва, но может выступать ограничением для свободной самореализации личности.

Ключевые слова: цифровые технологии; цифровая культура; цифровизация; сеть; культурная трансформация; свобода; самореализация; информационная безопасность; традиционная культура; цифровой разрыв.
\end{abstract}

Благодарность: статья подготовлена при финансовой поддержке РФФИ в рамках научного проекта № 19-011-00137 «Эволюция свободы в постсоветском обществе: социально-философский анализ и практическое моделирование» («The evolution of freedom in post-Soviet society: socio-philosophical analysis and practical modeling»).

\section{Для цитирования}

Мешкова Л. Н. Цифровые технологии как фактор трансформации культуры // Вестник Бурятского государственного университета. Философия. 2020. Вып. 3. C. 53-60.

Происходящие в настоящее время культурные процессы характеризуются повышенной динамикой. Современный мир мобилен, изменчив, «текуч» (3. Бауман). Многие изменения в сфере культуры связаны с процессом глобализации. Как «новый мегатренд» глобализация увеличивает экономическое и информационное взаимодействие, усиливает процессы межкультурной коммуникации, ведет к универсализации и интернализации таких культурных институтов, как образование, спорт и др. [16, с. 263]. Одним из проявлений глобализации стало распространение цифровых технологий и цифровой культуры.

Под влиянием цифровых технологий происходит трансформация образа жизни людей. Цифровизация затрагивает самые разные сферы деятельности чело- 
века. В первую очередь цифровые технологии упоминаются в связи с экономическими процессами, развитием цифровой экономики. Как указывает Т. Ф. Кузнецова, цифровая культура обозначает формирующийся этап культуры, соответствующий «цифровому обществу, ведущие черты которого видятся в цифровой экономике, преодолении аналоговой экономики как выражения прежних общественных устоев» [8, с. 233]. В то же время отмечается, что цифровая культура выражается в способах взаимодействия людей и технических средств в условиях все возрастающей компьютеризации и цифровизации в обществе $[19$, р. 66]. Цифровая культура как область современной культуры включает в себя не только владение современными техническими средствами, практику их использования, но и систему складывающихся в результате этого социальных взаимоотношений. Поэтому цифровая культура предполагает возникновение норм, ценностей, определенных культурных кодов, характерных только для нее.

Специфика современного состояния цифровизации состоит в том, что она проникла не только в профессиональную, деловую сферу деятельности, но стала неотъемлемой частью повседневной жизни. «Интернет во всем разнообразии его приложений является коммуникационной материей нашей жизни, охватывающей работу, личные связи и социальные взаимодействия в социальных сетях, информацию, развлечения, общественные услуги, политику и религию», - пишет М. Кастельс [3, с. 83]. В самом процессе цифровой трансформации нашей жизни выделяют два этапа. Если на первом, начальном, этапе усилия были направлены на повсеместное создание инфраструктуры доступа в Интернет с достаточной пропускной способностью, то на втором этапе главными становятся процессы, которые «превращают установленную мощность доступа в Интернет в приложения, которые могут быть непосредственно использованы людьми, бизнесом, административными и общественными организациями для достижения нового качества экономической и социальной жизни» ${ }^{1}$. Широкое использование цифровых технологий приводит к тому, что сейчас сложно разделить, как это было совсем недавно, реальность физическую и реальность виртуальную. Поэтому всё чаще используется термин «смешанная реальность», отражающий конвергенцию жизненного и цифрового пространства.

Взаимодействие между физической и виртуальной реальностью ставит проблему культурной трансформации, а точнее, проблему взаимодействия культурных кодов, транслируемых цифровой культурой, и культурных кодов уже сложившейся, в определенной степени традиционной, культуры. Эту проблему можно рассматривать и в более широком ключе: как взаимоотношение глобальной, универсализированной цифровой культуры и культуры региональной.

\footnotetext{
${ }^{1}$ Цифровая жизнь российских мегаполисов. Модель. Динамика. Примеры / Институт исследований развивающихся рынков бизнес-школы СКОЛКОВО, 2016 [Электронный реcypc]. URL: https://iems.skolkovo.ru/downloads/documents/SKOLKOVO_IEMS/Research_Reports/SKOLKOVO_IEMS_Research_2016-11-30_ru.pdf (дата обращения: 18.05.2019).
} 
В связи с этим можно задать несколько вопросов. Может ли цифровая культура повлиять на уже сложившуюся систему ценностей? Что нового может привнести цифровая культура в уже имеющуюся культурную картину мира? Какие новые аксиологические и деонтологические проблемы возникают в результате цифровой трансформации?

Эти вопросы связаны с коммуникативной и информационной природой цифровой культуры. Цифровые технологии большинством пользователей используют для общения, передачи или получения информации. Поэтому система норм, ценностей, установок, формируемых в рамках цифровой культуры, может широко транслироваться и распространяться.

Рассмотрение культурной трансформации, вызванной новыми технологиями, предполагает обращение к феномену свободы. Она всегда рассматривалась как сущностная характеристика человеческого бытия. Поэтому изменения условий существования человека так или иначе затрагивают сферу свободы человека.

Сами по себе новые цифровые технологии и устройства ценностно нейтральны. Но в зависимости от характера и целей их использования они могут как способствовать свободному развитию человека, так и порождать новые зависимости и ограничения.

В первую очередь на деятельность человека в рамках цифровой информативно-коммуникативной культуры влияет ее сетевая структура. Под ней понимается «децентрализованный комплекс взаимосвязанных узлов, способный расширяться путем включения новых звеньев, что придает сети гибкость и динамичность» [9, с. 49]. М. Кастельс подчеркивает, что именно современные технологические достижения в области микроэлектроники и нанотехнологий, повлиявшие на развитие современных средств коммуникации, способствовали социальной трансформации и превращению современного общества в сетевое [3, с. 40-41]. Он отмечает, что сетевая структура, в отличие от вертикальной (иерархической) организации, обладает такими характеристиками, как гибкость, адаптивность и способность к самонастраиванию [3, с. 39-40]. Сети являются подвижными, способны перенастраиваться в соответствии с изменяющимся окружением. Для них характерна полицентричность, равноправие, способность к самоорганизации и саморегуляции; низкая информационная сопротивляемость; нацеленность на высокую эффективность [6, с. 107]. При этом формируются сети разного типа, масштаба и охвата.

Полицентричность и равноправие в пространстве глобальной информационной сети Интернет проявляется в явлении «сетевого индивидуализма»- такой социальной структуры, где «индивидуумы строят свои сети, онлайновые и оффлайновые, основываясь на своих интересах, ценностях, склонностях и проектах» $[4$, с. 157-158]. Каждый интернет-пользователь является не просто потребителем информации. Современные технологии позволяют ему активно участвовать в информационном процессе, оставляя комментарии, высказывая свое мнение, откликаясь на сообщения в форумах, выбирая собственную траекторию поиска информации, размещая собственный контент, формируя социальные связи внутри интернет-сообществ. Участие как определяющий принцип цифровой культуры выделяет М. Деузе. Он отмечает, что «участие» вызвано появлением независимых медиа- 
центров с их стремлением к открытой публикации, к онлайн и офлайн совместному производству медиаконтента, с тем, что каждый может публиковать или загружать контент на веб-сайт [17, р. 67]. Процесс участия, по его мнению, проявляется в активном осмыслении представленной информации с открытой ответной реакцией на нее; в принятии и одновременно модификации и реформировании способов понимания реальности; в рефлексивном «собирании» наших собственных конкретных версий реальности.

Но не только интерактивное участие характерно для субъектов интернеткоммуникации. Цифровые технологии становятся инструментами для творческого поиска и самовыражения. Примером тому служат ведение блогов, размещение фотографий и видео, создание профилей в социальных сетях. Происходят изменения в организации профессиональной деятельности.

Благодаря развитию беспроводных соединений, постоянно возрастающему количеству подключенных к интернету электронных устройств становятся подвижными границы рабочего времени и рабочего места. В ряде профессий они теряют четкую фиксацию. Чертой современности становится радикальная делокализация наших взаимодействий с местами, вещами и друг с другом в пространстве и во времени $[11$, с. 46]. Однако влияние цифровых технологий на профессиональную сферу более глубокое, чем просто изменения места, времени, графика работы. Появляются новые способы вовлечения людей для решения производственных задач. Ярким примером тому является практика краудсорсинга, под которым понимается «передача определенных производственных функций неопределенному кругу лиц или решение общественно значимых задач силами множества добровольцев, координирующих свою деятельность с помощью информационных технологий» [15, с. 171]. Краудсорсинг широко используется при разработках программного обеспечения и мобильных приложений, в создании медиаконтента и т. д. Одним из первых примеров применения данной технологии является онлайнэнциклопедия «Википедия». В отечественной практике краудсорсинг использует в своей деятельности Сбербанк России, в частности, при работе над проектом «Сбербанк-21». Следует обратить внимание на мотивацию участия в краудсорсинговых проектах. Часто в качестве ведущего мотива выступает не денежное вознаграждение, а возможность самореализации, стремление заявить о себе, продемонстрировать свои способности, получить новые знания и навыки, повысить свой статус, престижность [15, с. 173]. Иными словами, мотивы имеют внутренний характер, основываются на свободном выборе. Таким образом, цифровая культура создает условия проявления личностной свободы как самореализации.

Возможности для самореализации личности в киберпространстве и связанные с этим ценностные установки отмечают многие исследователи. Самореализация помимо профессиональной деятельности может быть связана с тем, как индивид позиционирует, преподносит себя в виртуальной среде, какой образ создает, как формирует собственную виртуальную идентичность. Поэтому Н. Ю. Квашенко, анализируя ценностные ориентации в цифровой культуре, в качестве первой из них выделяет «повышение значимости установок на самопрезентацию в информационном пространстве» [5, с. 24]. 
В то же время увеличение степени свободы, которое вызывается новыми технологическими возможностями, ставит проблему ответственности за свои действия в информационно-коммуникативном пространстве. Возможность высказывать свое мнение, с одной - может способствовать развитию свободной дискуссии, но, с другой - может затрагивать достоинство личности и ограничивать права другого человека. В связи с этим встает проблема информационной безопасности в виртуальном пространстве, которая включает в себя следующие вопросы: сохранение конфиденциальности; распространение недостоверной или искаженной информации, вводящей в заблуждение пользователей; распространение информации, угрожающей физическому и психическому здоровью человека; размещение информации, призывающей к насилию, пропагандирующую ненависть по расовому или иному социальному признаку; манипуляция сознанием и поведением человека; нарушение прав интеллектуальной собственности $[2 ; 7 ; 12]$. В результате возникает необходимость морального и правового регулирования поведения интернет-пользователей. Обострение нравственных проблем свободы в киберпространстве, возникновение моральных дилемм привело к активному развитию таких направлений прикладной этики, как информационная этика, компьютерная этика [7]. Кроме того, глобальная информационная культура ведет к появлению этики цифрового мира, основными ценностями которой выступают ценности свободы, прав и достоинства личности [14].

Рассматривая влияние цифровой культуры на осознание и проявление свободы, необходимо обратить внимание на следующий момент: как происходит корреляция цифровой свободы с уже сложившимися жизненными установками и моделями поведения. Вопрос заключается в том, как происходит взаимодействие культуры сетевой, связанной с новыми инновационными технологиями, и культуры традиционной, построенной по иерархическому, вертикальному принципу. Если, как указывалось выше, для сетевой, цифровой культуры - подвижность, гибкость, то для традиционной иерархической структуры характерны устойчивость, последовательное движение информации, принцип субординации, высокая нормативность, медленное реагирование на ситуацию [6, с. 107].

Для иллюстрации «столкновения» установок цифровой культуры и установок традиционной культуры обратимся к результатам исследований, проведенных Московской школой управления СКОЛКОВО «Цифровая жизнь российских мегаполисов» (2016) и «Цифровая жизнь российских регионов» (2020). Данные исследования посвящены количественному измерению прогресса цифровизации в жизни современных российских городов и регионов, охватывая такие аспекты современной городской жизни, как транспорт, финансы, розничная торговля, здравоохранение, образование, СМИ и администрация. Было показано, что цифровые технологии стали значимым фактором общего воспринимаемого качества городской среды. В рамках указанных исследований рассматривалось соотношение между предложением и спросом цифровых услуг и технологий, выявлялись разрывы между ними. Выделим некоторые выводы, полученные в ходе данной работы. В результатах исследования 2016 г. отмечается, что «нарастающий разрыв корреляции спроса и предложения является выражением относительной слабости местной цифровой предпринимательской инициативы и нечувствительности фе- 
деральных сетевых игроков (банков, ритейлеров и т. д.), а также местных администраций к особенностям местного спроса» ${ }^{1}$. В отчете об исследовании 2020 г. указывается, что «общий цифровой разрыв в большей мере определяется различиями в уровне цифрового спроса, определяемым цифровыми навыками и компетенциями населения» ${ }^{2}$. Более того, утверждается, что если цифровой разрыв «первого уровня» - неравенство в доступе к цифровым сетям - сокращается, то разрыв «второго уровня» - неравенство в цифровых компетенциях и способах использования технологий - может расти ${ }^{3}$. В указанных выводах есть один общий, важный, на наш взгляд, момент: цифровой разрыв между спросом и предложением зависит в настоящее время не от наличия технических средств (они вполне доступны), а от желания, стремления и умения ими пользоваться как со стороны организаций, предприятий, так и со стороны населения, пользователей. Отмеченное же в исследованиях отсутствие инициативы в этом вопросе может быть связано в определенной степени с консерватизмом, инертностью, нежеланием менять стиль жизни и работы, страхом перед новыми технологиями, неуверенностью. Близкие суждения высказывают и другие исследователи. Так, Т. Д. Марцинковская, анализируя информационную социализацию подростков, отмечает, что проблема цифрового разрыва между подростками и учителями кроется не столько в недостаточном умении использования педагогами электронных средств информации, «сколько в отношении и доверии к ним... При этом они [педагоги] не видят уникальных возможностей культурного и познавательного развития в новых технологиях» [10].

Подобный консерватизм, т. е. стремление к привычным, устоявшимся способам работы, становится проявлением действия так называемых «ловушек для свободы» - морально-практических правил и жизненных установок, «которые удерживают человека в состоянии несвободы, признавая его лишь феноменальным существом, зависящим от законов природы, обстоятельств, судьбы, других людей (от природных и социальных условий)» [13, с. 177]. А. Г. Мясников, анализируя механизм действия «ловушек для свободы», отмечает их связь с традиционным сознанием. В качестве одной из функций «ловушек для свободы» выделяется «прагматичное формирование однообразных, предсказуемых общих целей жизнедеятельности и одинаковых средств их достижения в рамках сложившейся системы общественных отношений» [13, с. 178]. Подобное действие традиционных

${ }^{1}$ Цифровая жизнь российских мегаполисов. Модель. Динамика. Примеры / Институт исследований развивающихся рынков бизнес-школы СКОЛКОВО, 2016 [Электронный реcypc]. URL: https://iems.skolkovo.ru/downloads/documents/SKOLKOVO_IEMS/Research_Reports/SKOLKOVO_IEMS_Research_2016-11-30_ru.pdf (дата обращения: 18.05.2019).

${ }^{2}$ Цифровая жизнь российских регионов. 2020. Что определяет цифровой разрыв? / Институт исследований развивающихся рынков бизнес-школы СКОЛКОВО, 2020. [Электронный ресурс]. URL: https://iems.skolkovo.ru/downloads/ documents/SKOLKOVO_IEMS/Research_Reports/SKOLKOVO_IEMS_Research_Digital_life_of_russian_regions_2020-06-09_ru.pdf (дата обращения: 07.08.2020).

з Там же. 
установок как раз и вызывает у индивида недоверие к новым технологиям, ограничивает сферу свободной деятельности человека.

Однако взаимодействие традиционного сознания, традиционных установок и ценностей с установками и ценностями, утверждаемыми инновационной цифровой культурой, носящей глобальный характер, является достаточно сложным. Консерватизм, присущий традиционной культуре, не означает необходимость отказа от нее. Согласимся с позицией, что «успешная модернизация российского общества возможна на основе синтеза традиционных ценностей и ценностей инновации и самореализации, при этом такие ценности, как свобода, инновационность и самовыражение, определяют направленность развития, а традиционные ценности - устойчивость и стабильность социокультурного развития» [1, с. 24].

Таким образом, формирующаяся под воздействием новых технологий цифровая культура стала неотъемлемой частью образа жизни современного человека. Цифровые технологии проникают в самые разнообразные области деятельности человека, влияя на способ восприятия мира, трансформируя систему социальных связей, способствуя раскрытию способностей человека и его самореализации. Одновременно цифровизация нашей жизни ведет к осмыслению границ цифровой свободы, осознанию ответственности за свои действия в глобальном информационном пространстве. Актуальной и сложной проблемой становиться взаимодействие виртуального мира и ценностей культур региональных, национальных, этнических, так как их соединение, синтез становится средой, где происходит социализация подрастающего, «цифрового», поколения.

\section{Литература}

1. Авдеев Е. А. Социокультурные факторы трансформации системы ценностей российского общества в условиях глобализации: автореф. дис. ... канд. филос. наук: специальность 09.00.11 Социальная философия. Ставрополь, 2018. 29 с.

2. Гарипова Г. Р. Воздействие процессов глобализации на построение современной информационной картины мира // Общество: философия, история, культура. 2017. № 11. [Электронный pecypc]. URL: https://cyberleninka.ru/article/n/vozdeystvie-protsessovglobalizatsii-na-postroenie-sovremennoy-informatsionnoy-kartiny-mira (дата обращения: 04.08.2020).

3. Кастельс М. Власть коммуникации. М.: Изд. дом Высшей школы экономики, 2016. $564 \mathrm{c}$.

4. Кастельс М. Галактика Интернет: размышления об Интернете, бизнесе и обществе. Екатеринбург: У-Фактория, 2004. 328 с.

5. Квашенко Н. Ю. Влияние иносферы на ценностные установки личности в цифровой культуре // Научно-технические ведомости Санкт-Петербургского государственного политехнического университета. Общество. Коммуникация. Образование. 2020. № 1. C. $19-29$.

6. Коробейникова Л. А., Гиль А. Ю. Сетевые структуры в условиях глобализации // Известия Томского политехнического университета. 2010. № 6. С. 105-109.

7. Кот Я. И. Нравственные аспекты свободы в киберпространстве // Гуманитарный вестник. 2018. № 11(73) [Электронный pecypc]. URL: https://cyberleninka.ru/article/ n/nravstvennye-aspekty-svobody-v-kiberprostranstve (дата обращения: 04.08.2020).

8. Кузнецова Т. Ф. Цифровая культура // Знание. Понимание. Умение. 2018. № 4. C. 233-237. 
9. Лысак И. В., Косенчук Л. Ф. Современное общество как общество сетевых структур // Информационное общество. 2015. № 2-3. С. 45-51.

10. Марцинковская Т. Д. Информационная социализация в изменяющемся информационном пространстве // Психологические исследования. 2012. Т. 5, № 26. С. 7.

11. Митчелл У. Я++: Человек, город, сети. M.: Strelka Press, 2012. 328 c.

12. Мищериков А. А. Безопасность и свобода личности в информационном обществе: анализ проблемы // Теория и практика общественного развития. 2011. № 1. С. 39-42.

13. Происхождение, структура и функции ловушек для свободы: социально-философский анализ / А. Г. Мясников [и др.] // Контекст и рефлексия: философия о мире и человеке. 2019. Т. 8, № 2А. С. 173-185.

14. Немчина В. И., Сапунова Т. Г. Идентификационная дихотомия информационного общества: свобода и принуждение // Философия права. 2018. №4 (87). С. 42-47.

15. Нестик Т. А. Краудсорсинг как модель управления знаниями: социально-психологические особенности и ограничения // Экономические стратегии. 2014. № 6-7. С. 170174.

16. Федотова В. Г. Хорошее общество. М.: Прогресс-Традиция, 2005. 544 с.

17. Deuze M. (2006) Participation, Remediation, Bricolage: Considering Principal Components of a Digital Culture // The Information Society. 22. 2006. P. 63-75.

Статья поступила в редакиию 30.08.2020; одобрена после рецензирования 25.09.2020; принята к публикайии 28.09.2020.

\title{
DIGITAL TECHNOLOGIES AS A FACTOR OF CULTURE TRANSFORMATION
}

\author{
Lyudmila N. Meshkova \\ Cand. Sci. (Philos.), A/Prof., \\ Penza State University \\ 40 Krasnaya St., Penza 440026, Russia \\ lnmeshkova@rambler.ru
}

Abstract. The article discusses the impact of digital technologies on the modern cultural process. It is shown that the digitalization process leads to the emergence of a digital culture. Digital culture has become an integral part of business and everyday life, offered new opportunities for manifesting human freedom, for personal self-actualization. At the same time, the development of digital culture creates new moral and legal challenges related to cyberspace security. We have noted that the problem of interaction of digital culture as a culture of a global type with traditional culture is becoming urgent. The conservative attitudes of traditional consciousness can be an obstacle to the development of new digital technologies. This is not only one of the reasons for the digital divide, but it can also restrict the free self-actualization of the individual.

Keywords: digital technologies; digital culture; digitalization; network; culture transformation; freedom; self-actualization; information security; traditional culture, digital divide. 